\title{
Strengthening Scientific Research Ability of Undergraduates, Cultivating Practical and Innovative Talents
}

\author{
Yuan Lei and Wang Cheng Hua
}

\begin{abstract}
Undergraduates doing scientific research is an effective way to cultivate innovative talents. The paper introduces some practices and experiences of Nanjing University of Aeronautics and Astronautics in strengthening undergraduates' scientific research ability as to cultivate practical and innovative talents. The school develops a training system of cultivating innovative talents, featuring a practical teaching system based on engineering practice and a continuous comprehensive student-centered scientific innovative system.
\end{abstract}

Index Terms-Engineering education, practical and innovative activity, undergraduate research.

\section{INTRODUCTION}

In July, 2010, National Plan for Medium and Long-term Educational Reform and Development (2010-2020) established the reform plan to improve the quality of advanced education and talent cultivation and explicitly put forward to a mode of cultivating innovative talents, proposing that the core objective of advanced education and the key point of research on educational reform of advanced education should be to cultivate innovative talents. In 1998, the Boyer Commission on Educating Undergraduates in the Research University published Reinventing Undergraduates Education: A Blueprint for America's Research Universities and pointed out that "exploration, investigation and discovery" was the core of universities and everyone in the university should be the "discoverer" and "learner" and proposed that research universities should take full advantage of its superiority in research and get undergraduates involved [1]. Therefore, how to deepen the educational reform, strengthen undergraduates' scientific research ability and explore a training mode for talent cultivation has become an important realistic project for research-oriented universities [2].

\section{Changing Teaching Concept And Establishing THE IDEA OF CULTIVATING TALENTS CENTRE ON IMPROVING PRACTICAL AND INNOVATIVE ABILITIES}

Nanjing University of Aeronautics and Astronautics (NUAA) is a national key university focusing on engineering combined with science, with distinct characteristics of

Manuscript received April 10, 2013; revised July 17, 2013.

The authors are with the Office of Academic Affairs, Nanjing University of Aeronautics and Astronautics, Nanjing, Jiangsu China (e-mail: yuanlei@nuaa.edu.cn, chwang@nuaa.edu.cn).
Aeronautics, Astronautics and Civil Aviation. The school takes improving students' practical and innovative ability as its core educational objective. It integrates quality educational resources, sets up a progressive talent training system and constructs a comprehensive practical and innovative system and discipline competitive platform.

According to the new requirements for talent training in a new era, NUAA gives a profound study to the new connotation of practical ability and innovative spirit and fully realizes that carrying on engineering practical education and cultivating innovative talents is an important policy for schools to face the future and meet the needs of reform and development of advanced education and also an inner requirement for schools to deepen its educational reform, improve its teaching quality, promote students' comprehensive quality for overall development and increase their competence for employment and development [3].

III. ENHANCING THE INTEGRATION BETWEEN THEORY AND PRACTICE AND PERFECTING THE Distinct TALENT TRAINING System Featuring AERONAUtics, Astronautics AND CIVIL AVIATION

\section{A. Reform the Teaching Mode and Strengthen the Penetration of Scientific Research into Teaching}

Undergraduates doing research is a new teaching theory put forward to meet the requirements of the era of knowledge economy and to counter the disadvantages of the traditional receptive learning mode. It is a training mode for cultivating innovative talents with problem-exploring, knowledge-discovering and ability-developing as the core objective. It requires to explore research-oriented teaching mode actively, to integrate teaching and scientific research, to strengthen teaching based on scientific research and the penetration of scientific research into teaching. It requests teachers to carry out scientific research besides teaching and to give enlightenments to students with innovative thoughts by imparting his own innovative achievements, experience and methods of scientific thinking to students [4]. The integration between teaching and scientific research enables students to know and grasp the latest knowledge of the field, learn methods of scientific research and develop their innovative awareness [5]. Meanwhile, it also requires the school to create a good environment to help students to participate in scientific and innovative activities as early as possible and to cultivate their innovative awareness and innovative ability through the research practice. 


\section{B. Perfecting the "Progressive, Four-Leveled, Multi-Moduled and Menu-Typed" Practical Teaching System}

Following the idea of "reinforce the basic knowledge, strengthen practice" and the teaching rules of being progressive and combining knowing and doing, the school takes improving students' innovative and practical abilities as the core, makes overall plans of theory teaching and practice teaching and pay great attention to integrating theory with practice. The school reforms the content and methods of practice and integrates compulsory experiments and optional experiments, curriculum design and system design, basic skill training in class and cultivating projects independently outside class, with which the training of practical and innovative abilities dwells in the whole process of practice. It perfects the progressive, four-leveled (experimenting, designing, synthesizing and innovative levels), multi-module and menu-typed" practical teaching system and improves students' practical and innovative abilities progressively and systematically.

\section{Constructing and Implementing a Comprehensive System of Scientific and Technological Innovation}

Guided by "Challenge Cup" competitions and National Undergraduate Electronic Design Contests, the school takes undergraduates' innovative programs and teachers' research projects as the carrier to carry out rich innovative activities outside class, such as Scientific and Technological Innovation Solon, Science and Technology Festivals. The school puts efforts in constructing an "alternative, participative and open" innovative system to promote undergraduates to grasp new knowledge, new techniques and enhance their exploring ability and innovative thinking. All these enable students to enjoy the pleasure of participating in scientific and technological innovation activities and finally lead students to creations.

\section{Integrating Resources and Establishing a Comprehensive, Advanced and Open Practical and Innovative Platform}

The university attaches great importance to the construction of innovation labs and invests special funds to set up common platforms for innovation training, e.g. small aircraft innovation labs, mathematical modeling labs, electric and electronic innovation labs and so on, altogether 17 innovation labs for students and the staff. It also sets up 7 subject labs for postgraduates, namely, Flight Detection and Control, Hypersonic Gas dynamics, New Flight Controlling Technology, Technology in High Precision Machining Tools Manufacturing of Advanced Composite Materials and Structure, Aviation Intellectual Property and Software Quality Assuring and Testing Technology. The construction of labs strengthens the formation of experimenting and practical teaching platforms to carry out innovative experiments and subject research.

\section{IMPLEMENTING InNOVATION TRAINING Plans, SETting UP DISCIPLINE COMPETITION PLATFORMS AND STRENGTHENING TRAINING OF UNDERGRADUATES' RESEARCH ABILITY}

\section{A. Establishing a Four Level Innovation Training System} (of the State, the Province, the University and the College)

The undergraduates' innovative training system is guided by the National Training Programs of Innovation and Entrepreneurship for Undergraduates. Based on the working thought -driving with interest, stressing the process, independent-managing, arousing vitality - the university sets up a new hierarchical innovative training system, which involves a united management of both university and college, taking in four levels of programs: of the state, the province, the university and the college, bringing in subjects from both inside and outside the university, and establishes research and innovation funds and practices a tutorial system for undergraduates as a part of the undergraduates training program, It provides undergraduates fund and a good environment for scientific research, promotes the spread of undergraduates' research culture and academic development, enhances the information exchanges among students and between students and teachers and provides a platform for undergraduates to display their research findings and spurs students and teachers to actively participate in scientific research and guides students to carry out innovative training activities in scientific research to spur their innovative thinking and awareness.

NUAA makes great efforts to establish students' innovation teams, investing special funds to establish Innovation Theme Zone. With stable research subjects, it achieves a continuity and a further and deeper development in research through teachers' guidance and students' autonomous management and also realizes the goal of training students' innovative ability through the four stages "awareness, participation, management, guidance". The construction of interdisciplinary innovative teams, exchanges between teachers and students and an organic integration of teaching and researching have been accelerated through project-topic declaration, team member interviews, regular team discussions and research team admission for excellent members. The establishment of Innovation Theme Zone has created an accumulation area for innovative trainings and enlarged the scale and impact of innovative activities.

Over the past two years, over a thousand training projects of the state, the province, the university and the colleges have been established, covering about $50 \%$ of the students.

Favorable innovative atmosphere becomes a fertile land for outstanding innovation achievements. In 2011, "Phoenix Wings", established spontaneously by students from Douser Innovation Theme Lab of NUAA appeared as the only team from China in Airbus' Fly Your Ideas Challenge finals and beat 315 teams built by over 2600 students from all over the world and got the final champion.

\section{B. Attach Great Importance to the Construction of Students' Discipline Competition Platform}

Discipline competition can guide and encourage undergraduates to be innovative and to confront various challenges, which are far superior to common teaching methods in training students' professional qualities and strong will, therefore discipline competition is an important way to cultivate students' practical innovative ability, pioneering ability and team work spirit [6]. The school 
establishes a hierarchical, comprehensive, stereo-network for discipline competition in various levels: the international, national, provincial, municipal and school levels, and by implementing a series of administrative principles and incentive mechanisms, opening laboratory policies and constructing campus culture, the school ensures the standardization and long-term effect of the students' discipline competition and put into full display the unique effect of discipline competition on cultivating innovative talents. This practice has brought about great effects on educational reform and also great achievements.

For example, in 2011, the school had about 20,000 students attending various competitions inside and outside the school, among which over 7000 students attended in about 100 provincial and above competitions and 646 students were awarded a prize. In the National Undergraduate Electronic Design Contest, students from NUAA won two First Prizes, four Second Prizes. In the past five "Challenge Cup" National Undergraduate Curricular Academic Science and Technology Works, students won 4 Special Prizes, 11 First Prizes, 10 Second Prizes, and 5 Third Prizes, and for five times won the Challenge cup, among which, in 2011, the school, scoring 370, ranked second in the all the universities attending the competition. The school is also in a leading role in the state in the past four "Challenge Cup" Business Plan Competitions, winning 6 gold medals, 2 silver medals and 4 bronze medals.

\section{Planning of DeVeloping Undergraduates' SCIENTIFIC RESEARCH AND CULTIVATING PRACTICAL AND INNOVATIVE TALENTS}

\section{A. Expand the Coverage o Undergraduates Innovative Experimentation Project and Attract More Undergraduates to Get Involved}

It is important to attach great importance to undergraduates doing research culture and provide more opportunities for undergraduates to attend research and innovative activities by supporting diverse projects on undergraduates' scientific research and innovative activities.

\section{B. Perfect the System of Undergraduates Doing Scientific Research and Practical Innovation and Construct Diverse Platforms for Communication and Activities}

Organizations and meetings on undergraduates' scientific research and innovative activities should be encouraged and supported. Students' compositions can be displayed in presentation, posters and performance, which will not only enhance students' enthusiasm on participating in research and innovative activities but also improve their communicative abilities. Various ways can be taken to improve research atmosphere in higher education institutions and to provide more resources to undergraduates' research and innovative activities. For example, meetings can be organized to inspire discussions and exchanges among teachers; websites can be set up for undergraduates' research and innovation and research guides and journals for undergraduates can be published.

\section{CONCLUSION}

The paper introduces some practices and experiences of NUAA in strengthening undergraduates' scientific research ability, provides a practical way of further strengthening undergraduates' scientific research ability and exploring a training mode for innovative talents by setting up a progressive talent training system and a comprehensive practical and innovative system.

\section{REFERENCES}

[1] Z. Li, F. Lin, and K. C. Lu, "American undergraduate research and its inspiration to China," Research in Higher Education of Engineering, vol. 3, pp. 79-85, 2009.

[2] J. L. Pan and F. Gong, "Undergraduate education: Research university's core mission," China University Teaching, vol. 2, pp. 92-94, 2010.

[3] M. J. Chen, G. H. Gao, H. G. Zhang, H. Zhu, G. Q. Song, and F. Tai, "Building science and technology competition platform to promote the cultivation of innovative talents," China Modern Educational Equipment, vol. 23, 2012.

[4] H. L. Wang and X. L. Meng, "The cultivating model for innovative talents integrating teaching, research and production," Value Engineering, vol. 28, 2011.

[5] C. H. Dang and C. H. Liu, "The researches and practices of developing undergraduate education system of research university," China University Teaching, vol. 3, 2011.

[6] B. C. Zhang and H. F. Liu, "Building a comprehensive system of practical teaching and enhancing cultivation of practical capabilities," Experimental Technology and Management, vol. 4, 2012.

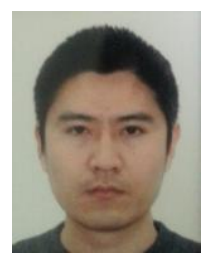

Yuan Lei was born in Jiangsu, China on April 18, 1979. $\mathrm{He}$ obtained his bachelor degree in mechanical engineering and automation from Nanjing University of Aeronautics and Astronautics, China in 2001. He is currently working toward master's degree in Nanjing University of Aeronautics and Astronautics. His research interests are software engineering and educational research.

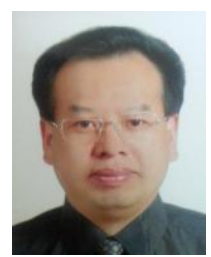

Wang Cheng Hua was born in Jiangsu, China on October 9, 1963. He is a professor and doctoral supervisor at Nanjing University of Aeronautics and Astronautics. His main research interests include design, test and verification of very large scale integration (VLSI), circuit theory and electronic system design, and the internet of things technology. He is the dean of Academic Affairs office of Nanjing University of Aeronautics and Astronautics. 